\section{Yellow fever risk in Asia-Pacific region}

The surge in air travel and the adaptive distribution of mosquitoes as a result of urbanization and climate change have accelerated the spread of chikungunya and Zika viruses over the past few years. Yellow fever could similarly spread to the Asia-Pacific region, previously considered off-limits to the virus (see Nature 532, 155-156; 2016). Scientists and public-health officials must take swift preemptive action, given that the area has an unvaccinated population of more than two billion people and a limited infrastructure for mounting a response (see go.nature.com/2dtbo6o).

A priority is to collect evidence on the region's mosquito populations, which include Aedes aegypti, Aedes albopictus and Aedes scutellaris. Scientists must study the mosquitoes' competence as vectors for the yellow fever virus, as well as their distribution, biology and susceptibility to insecticides.

Effective surveillance will be crucial. Diagnostic capacity must be improved to distinguish the yellow fever virus from the many other flaviviruses that circulate in Asia. Renewed research into vaccines is also warranted to support a coordinated global response to future outbreaks. Paul T. Brey Institut Pasteur of Laos, Vientiane, Laos.

Didier Fontenille Institut Pasteur of Cambodia, Phnom Penh, Cambodia.

Hong Tang Institut Pasteur of Shanghai, Chinese Academy of Sciences, Shanghai, China. htang@ips.ac.cn

\section{Don't reject evidence from CFS therapy}

We welcome your article on research into chronic fatigue syndrome (CFS), also known as myalgic encephalomyelitis or systemic exertion intolerance disease (see Nature 553, 14-17;
2018). In our view, however, you underestimate the benefits of current treatments: namely, graded exercise and cognitive behaviour therapy (CBT).

As you point out, people with the disease often feel ignored or dismissed by the medical profession - a situation that, as clinicians, we deplore. It is regrettable that some patients and others link behavioural treatments with dismissal of a person's condition, when in fact these therapies can be beneficial. Aside from the results of the PACE trial you mention (co-authored by two of us, T.C. and M.S., among others), further scientific evidence supports the effectiveness of interventions such as exercise and CBT (see, for example, L. Larun et al. Cochrane Database Syst. Rev. http://doi.org/ cjp6; 2017 and J. R. Price et al. Cochrane Database Syst. Rev. http://doi.org/dcs37d; 2008).

We think that patients deserve the best research and treatments. In our view, there is no place for stigmatizing any avenue of research or therapy that might help us to improve the lives of people with this long-term debilitating illness.

Michael Sharpe University of Oxford, UK.

Trudie Chalder Guy's, King's and St Thomas's School of Medicine, London, UK.

Jon Stone University of Edinburgh, UK. michael.sharpe@stx.ox.ac.uk Competing financial interests declared (seego.nature.com/2at6ng).

\section{Mentoring: a way to help mental health}

We contend that the incentive for faculty members to invest in mentoring is limited because of the disempowering structure of academia (see Nature 552, 5; 2017). This leaves graduate students and postdocs with a sense of isolation and without perspective on their accomplishments, both of which contribute to the mental-health problems experienced by many junior researchers.

Discussion of these mentalhealth issues has so far focused on strategies for coping with work pressures, for instance by achieving better work-life balance, finding meaning in outreach activities and seeking counselling (see, for example, Nature 545, 375-377; 2017 and Nature 539, 319-321; 2016).

As graduate students, we want instead to shift the discussion to the misplaced incentives in academia that undermine the well-being of both faculty members and students.

Faculty members are expected to excel simultaneously as principal investigators, educators, advisers and administrators. Their job security, however, is determined by the number and perceived impact of papers published and grants secured. This leaves them with little motivation to invest in the mentoring that stands to boost our collective well-being and sustainability.

Rather than place the burden on students to cope with depression, anxiety and burnout, we call on our entire academic community to address the underlying structural problems in academia that cause these mentalhealth issues in the first place.

Tatyana Perlova ${ }^{\star}$ University of Illinois at Urbana-Champaign, USA.

perlova2@illinois.edu

${ }^{\star}$ On behalf of 5 signatories (see go.nature.com/2rau64o for full list).

\section{Mentoring: a rung on the career ladder}

As a recipient of a US

Presidential Award for

Excellence in Science,

Mathematics and Engineering

Mentoring, I suggest that skills in mentoring should be made a condition for hiring faculty members. Mentoring success should also be included as a criterion for tenure and promotion. This would catapult mentoring to prominence
(Nature 552, 5; 2017).

At the California State University in Northridge, we have shown how well this tactic works. When hiring dozens of faculty members (Nature $\mathbf{5 3 8}, 171 ; 2016$ ), we included rigorous evaluations of their teaching and mentoring skills as an essential requirement in addition to their publication records.

The initiative helped to put the university in the top 25 North American institutions classed as 'Rising stars' in 2016 (see go.nature.com/2dfvirb). Steven B. Oppenheimer California State University, Northridge, California, USA. steven.oppenheimer@csun.edu

\section{Statistics: prevent $P$-value parroting}

In the same issue in which you propose 'Five ways to fix statistics' (Nature 551, 557-559; 2017), seven of the nine research papers in the biological sciences include $P$ values with their figures. In my view, this convention is questionable in most cases, given that the large statistical effects are immediately evident from the respective plots.

To help to fix statistics, I urge authors to instead report a $P$ value only when it conveys useful information and is essential for the interpretation of results.

Joachim Goedhart University of Amsterdam, the Netherlands. j.goedhart@uva.nl

\section{CORRECTION}

The Outlook article 'The struggle to do no harm' (Nature 552, S74-S75; 2017) mistakenly claimed that the biopharmaceutical firm Cellectis had not responded to requests for interview. $A$ comment from the company is now included in the online version of the story (see go.nature.com/2owayrn). 